\title{
LEGIBILITY
}

A major purpose of the Technical Information Center is to provide the broadest dissemination possible of information contained in DOE's Research and Development Reports to business, industry, the academic cornmunity, and federal, state and local governments.

Although a small portion of this report is not reproducible, it is being made available to expedite the availability of information on the research discussed herein.






\title{
title: $\quad$ COUPLING.IMPEDANCE AND RESPONSE- CHARACTERIZATION MEASUREMENTS OF A PROTON STORAGE RING WALL-CURRENT MONITOR
}

SUBMITTED TO:

\author{
L. S. Walling \\ D. McMurry \\ H. A. Thiessan \\ D. V. Neuffer
}

LA-UR- $-89-936$

DE89 009281

\section{DISC 'H,AIMER}



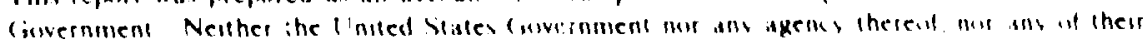

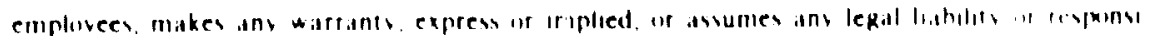



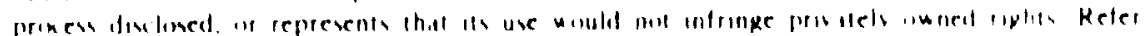

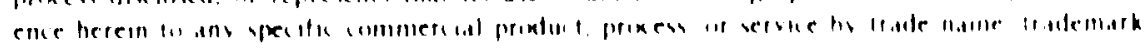



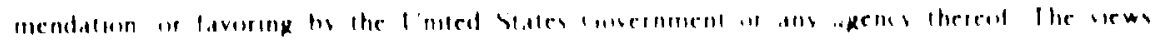

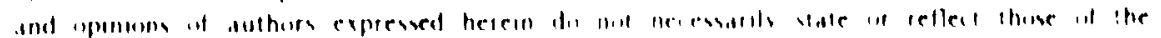

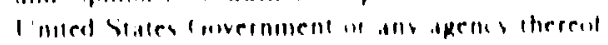

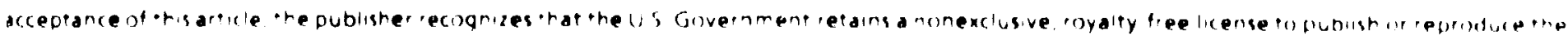

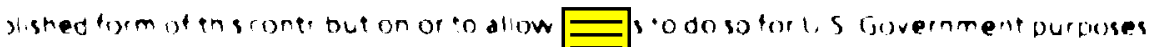

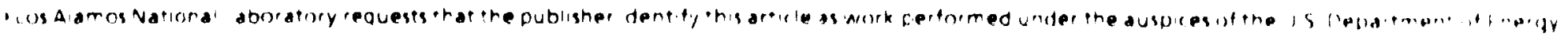

$\therefore \quad 3 \%$ is

us Alamos Nationall aboratory is Alamos New Mexico 87545 


\section{COUPLING-IMPEUANCE ANI) RESPONSH-CHARA('TERIZATION MEASLREMHNIS OF A PROTON STORAGE RING; WALL-CIJKRENT MONITOK*}

\section{I.inda S. Walling, D. E. McMurry, H. A. Thiessen, and I avic Neuffer}

MS-H817, Ios Alamos National Laboratory, Los Alamos, NM 87545

\section{Abstract}

This paper describes a method to measure the response of a beam current monitor and reports response and impedance measurement results for a Proton Storage Ring (PSE) wall current monitor.

\section{Introduction}

We have reported a Through-Short-Delay (TSD) calibration method for making coupling-impedance ineasurements.' We now describe extending this method to measure the response of a current monitor that is imbedded within hardware that interfaces to a network analyzer (Fig. 1). We utilize error correction parameters that are generated using the TSD-:alibration to calculate the actual current present al the current monitor.



rig. 1. Physical repreanlation of experiment Vote that the makhing sections orienther side of the lest deviee do nist neressarily represent a low SWK

\section{Mathod}

The measurement has five stips

1. Perfurm the TSI) culibration (Fik. 2). This yields the scatering parameters of the $(w 0)$ error networks. SA and SBB



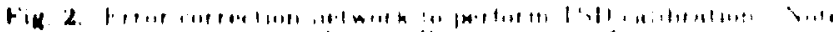

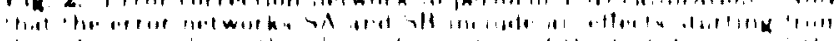

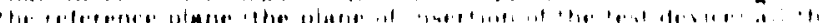

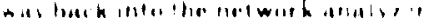

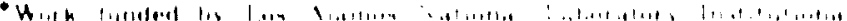





2. Insert the current moniur (Fig. 3 ), terminating its readout terminals in their respective characteristic impedances. Measure the s-parameters and apply the calibration (de-imbed $S$, the s-parameters of the current monitor, from the measured $s$ parameters using $S A$ and $S B$.

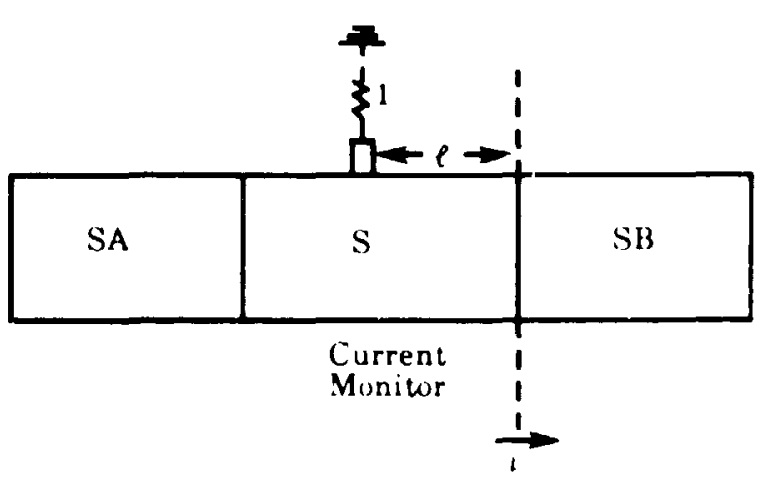

Fig. 3. Measures, the a parameters of the eurent momitul

3. Calculate 1, the current at the mon wr. This can be done by analyzing the flow diagram of the three networks (Fig 4 ) $w$ yield the forward (a) and reverse (b) waves at the reference plane. Analyzing the now diagram yiclds the folluwing



and

$$
\frac{n}{4 ! 11}
$$

where

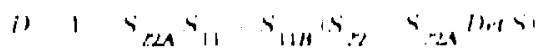

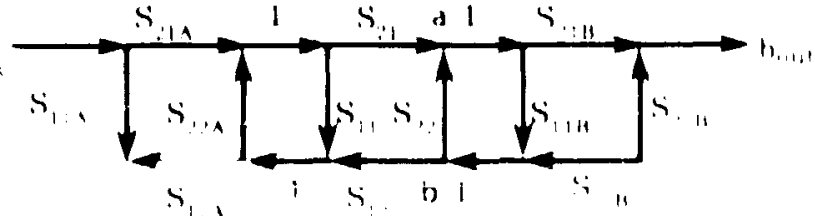

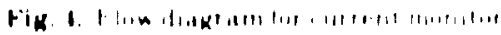

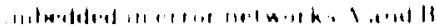

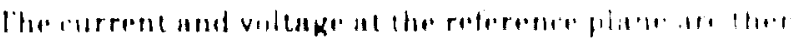

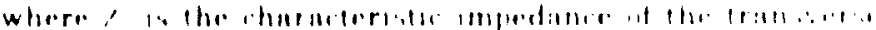


and the terit devine

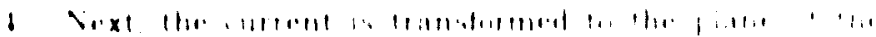

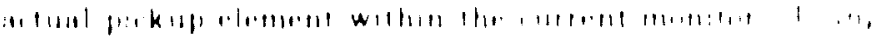
I1, 1111$)$ 'malrix 


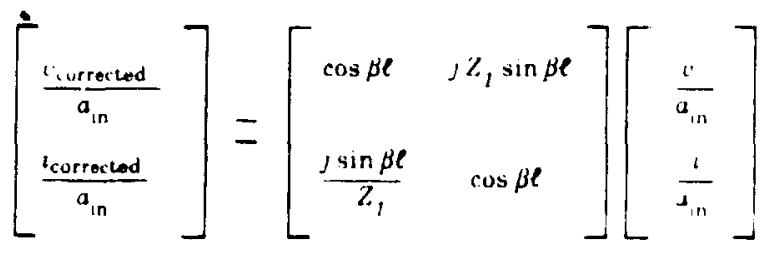

the corrected current is calculated:

$$
\frac{t_{\text {carrectod }}}{a_{11}}=\rho\left(\frac{v}{a_{1 n}}\right) \frac{\sin \beta !}{Z_{1}}+\left(\frac{1}{a_{1 n}}\right) \cos \beta \ell
$$

5. Finally, the network analyzer is connected to the output si nal port of the current monitor (Fig. 1), the disconnected end is terminated in its characteristic impedance, and trangmission $T$ is measured, yielding

$$
\Gamma=\left(u_{\text {iut }}, \sqrt{Z}_{0}\right) / a_{\text {in }} \text {. }
$$

where $z_{0}$ is the characteristic impedance of the network analyzer. The response is then

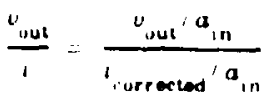

where

$$
\frac{\text { ".sut }}{u_{\text {in }}} r \sqrt{\%_{0}}
$$

\section{Measurement Results}

Figure 5 is a diagram of the wall current monitor that we measured. It has eight $50 \Omega$ pickups. The entire monitor is enclused in a box lined with ferrite. Four of the pickups are connected $u$ une four way combiner, the othe: four w another four way combiner. Then, the outputs of the two four way cumbiners are connecled $w$ a two-way combiner. the monitor was measured both with the combiners and withoul leerminating connectors at the case). A wire of dinmeter $1.59 \mathrm{~mm}$ way used for the center conductor. yielding a line impedance $Z_{1}=248 \Omega$. The line impedance in the regluns where cerninir is present are slightly different. $Z$, : $257 \Omega$



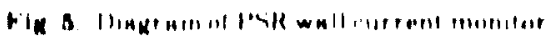

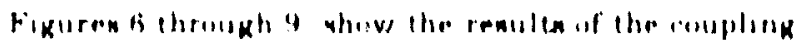
impertuner mensurement Without comboners, the menaured

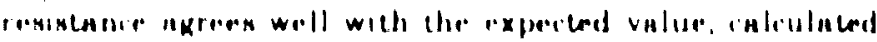

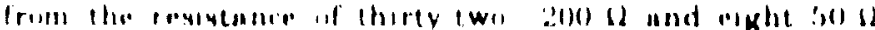

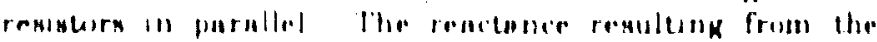

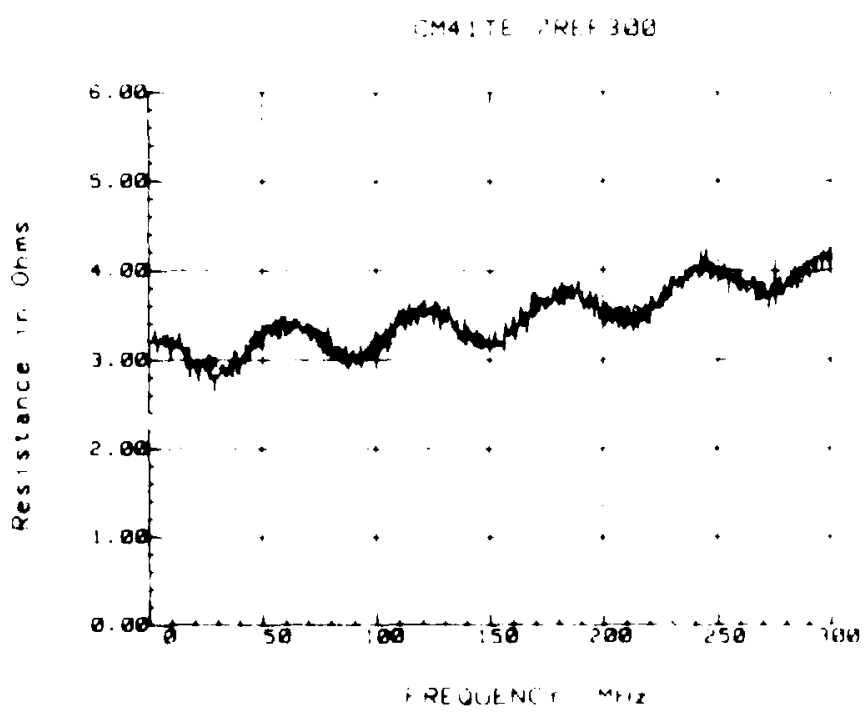

Fig. 6 Real part of coupling ampedance. ase: unh

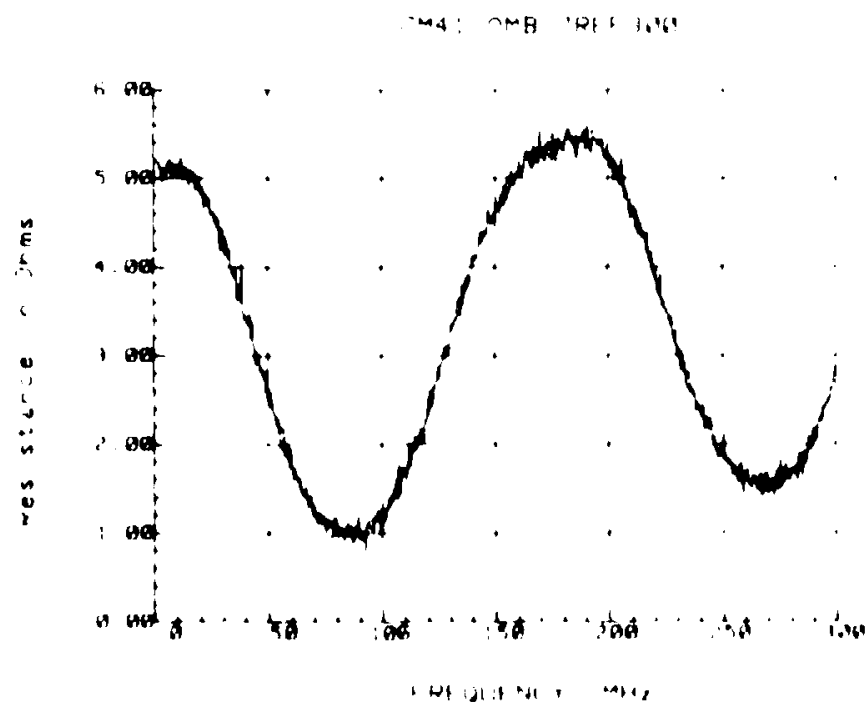

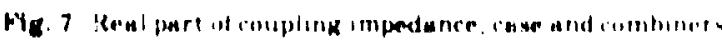



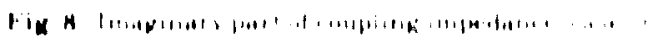


ceramic and steps in the outer conducur at the ceramic insets is $10 \Omega$ at $300 \mathrm{MHz}$. The response for a single pickup is shown in Fig. 10. The response for the combined pickup siganals is shown in Fig. 11. These are currecled dala, as described in the methods section. In addition, all data has been corrected for line attenuation betwean the pickup port and the network analyzer

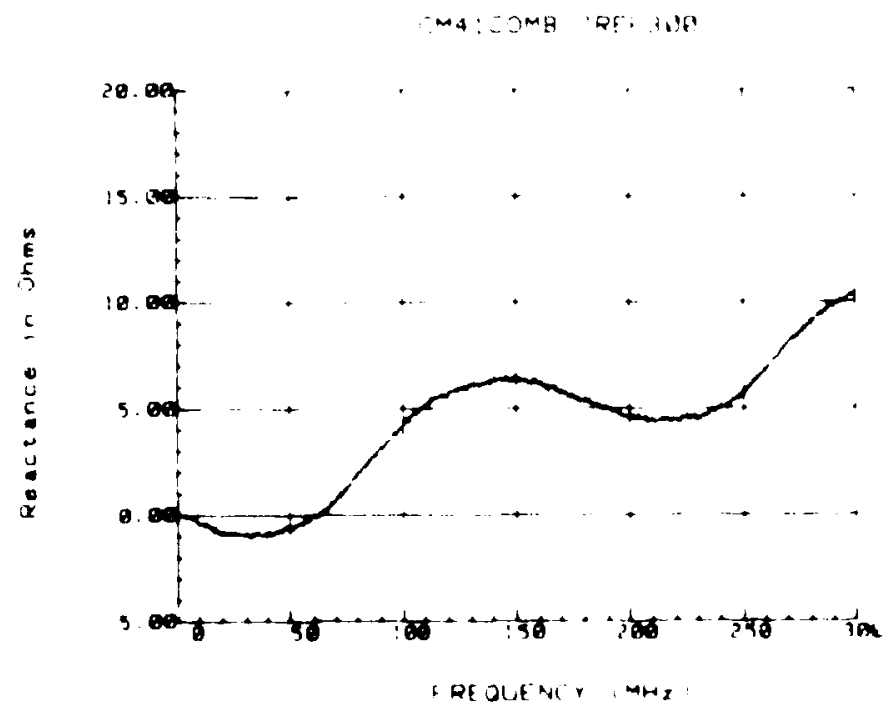

Me. 9 Imannary part if coupling

Hoipedunce casery and cumbinery

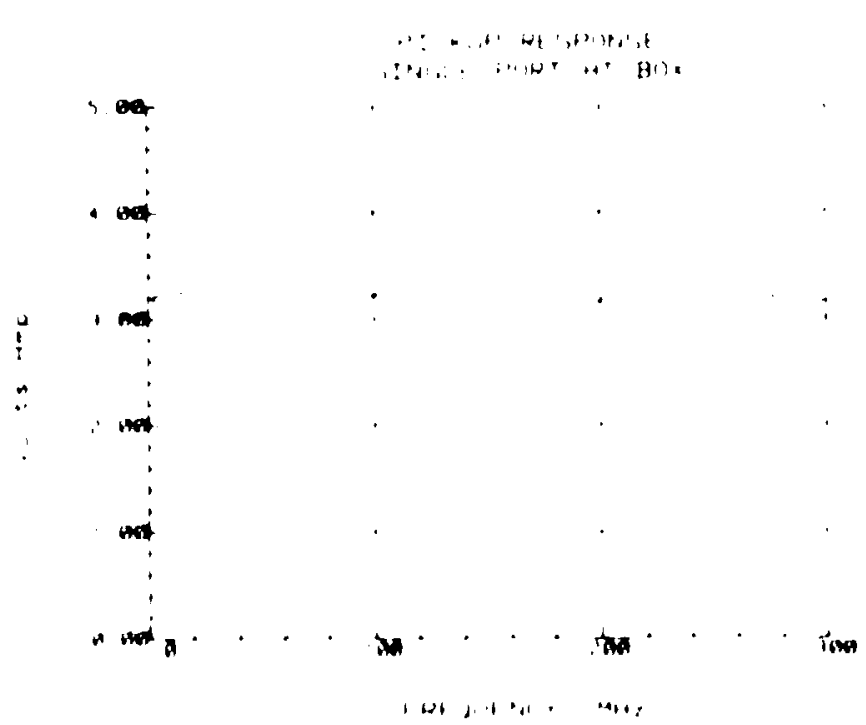

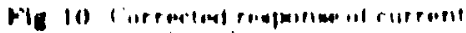

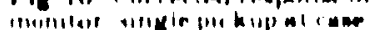

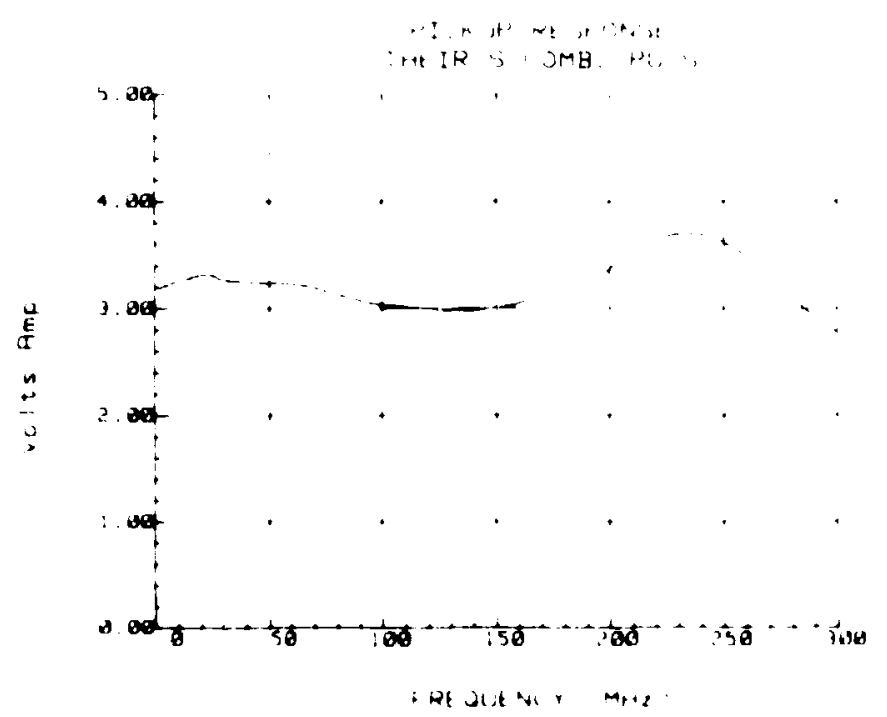

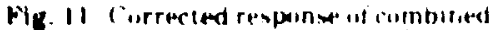
pickups casing custom two wat vilitler

The results show a marked increase in impedaice th.s: is due $w$ the cables and combiners

\section{Heferences}

I L. S. Walling, I) E. McMurry, D. Nourer, wad HI A Thiessen. Transmisaion Line Impedacs Measure mente for an Advanced Hadron Facility." I Ass Alamos National Laburawry report LA L:K 883533. submitted to Nucl Instrum and Methods 